\title{
Correction to: Prediction of Persistent Pain Severity and Impact 12 Months After Breast Surgery Using Comprehensive Preoperative Assessment of Biopsychosocial Pain Modulators
}

Kristin L. Schreiber, MD, PhD $^{1}$ (D), Nantthansorn Zinboonyahgoon, MD $^{2}$, K. Mikayla Flowers, $\mathbf{M S}^{\mathbf{1}}$, Valerie Hruschak, PhD $^{1}$, Kara G. Fields, $\mathbf{M S}^{1}$, Megan E. Patton, $\mathbf{B S}^{1}$, Emily Schwartz, BS ${ }^{5}$, Desiree Azizoddin, $\mathrm{PhD}^{3}$, Mieke Soens, $\mathrm{MD}^{1}$, Tari King, $\mathrm{MD}^{4}$, Ann Partridge, $\mathrm{MD}^{5}$, Andrea Pusic, $\mathrm{MD}^{4}$, Mehra Golshan, $\mathrm{MD}^{6}$, and Rob R. Edwards, $\mathbf{P h D}^{1}$

${ }^{1}$ Department of Anesthesiology, Perioperative and Pain Medicine, Brigham and Women's Hospital, Harvard Medical School, Boston, MA; ${ }^{2}$ Department of Anesthesiology, Siriraj Hospital, Mahidol University, Bangkok, Thailand; ${ }^{3}$ Department of Psychosocial Oncology and Palliative Care, Dana Farber Cancer Institute, Harvard Medical School, Boston, MA; ${ }^{4}$ Department of Surgery, Brigham and Women's Hospital, Boston, MA; ${ }^{5}$ Department of Medical Oncology, Dana-Farber Cancer Institute and Department of Medicine, Brigham and Women's Hospital, Harvard Medical School, Boston, MA; ${ }^{6}$ Department of Surgery, Dana-Farber/Brigham and Women's Cancer Center, Harvard Medical School, Boston, MA

\section{CORRECTION TO: ANN SURG ONCOL} HTTPS://DOI.ORG/10.1245/S10434-020-09479-2

This study was supported by grants from the NIH/ NIGMS (K23 GM110540 and R35GM128691) (KLS).
The grant information for Kristin L. Schreiber in the original online version of the article was corrected.

Publisher's Note Springer Nature remains neutral with regard to jurisdictional claims in published maps and institutional affiliations.

The original article can be found online at https://doi.org/10.1245/ s10434-020-09479-2.

(C) Society of Surgical Oncology 2021

Published Online: 16 August 2021

K. L. Schreiber, MD, PhD

e-mail: klschreiber@bwh.harvard.edu 